\title{
A EXECUÇÃO CIVIL FRUSTRADA E A RESTRIÇÃO AOS SIGILOS BANCÁRIO E FISCAL
}

Luciana Veiga Caires*

SUMÁRIO: 1. Introdução. 2. A busca de bens pelo credor. 3. Sigilo Bancário. 3.1. Definição e Fundamentação Juridica. 4. Sigilo Fiscal. 5. A relatividade do direto aos sigilos bancário e fiscal. 6. A quebra dos sigilos bancário e fiscal em face do interesse da Justiça. 7. Conclusão. 8. Bibliografia.

SUMMARY: 1. Introdution. 2. The search of properties by the creditor: 3. Banking Secret. 3.1. Definition and Juridical Basenent. 4. Fiscal Secret. 5. The relativity of the right of banking and fiscal's secrets. 6. The breach of banking and fiscal's sectets in front of Justice's interest. 7. Conclusion. 8. Bibliography.

SUMARIO: 1. Introducción. 2. La busqueda de bienes por el demandante. 3. Secreto bancario. 3.1 Definición y Fundamentación Juridica. 4. Secreto Fiscal. 5. La relatividad del derecho al secretos bancario y fiscal. 6, La violación dos secretos bancario e fiscal a favor del interés de la Justicia. 7. Conclusión. 8. Bibliografta.

RESUMO: Apresenta a problemática relativa à inexistência de bens penhoráveis no processo de excução, particularmente no tocante à questão dos sigilos bancário e fiscal. Investiga a natureza juridica desses dois institutos, bem como seu enquadramento legal, enquanto espécies do direito a privacidade. Aborda, ainda, os procedimentos que poden ser adotados pelo exeqüente na busca de bens do executado, bem como os óbices legais ligados aos sigilos bancário e fiscal. Ressalta a execuçáa civil frustrada como uma das hipóteses que ensejam restrição aos sigilos bancátio e fiscal, sustentando que a decisão do juiz que indefere o pedido de expedição de oficios à Receita Federal e ao Banco Central, risando a busca de informaçóes sobre eventuais bens de propriedade do executado, sob o argumento de ofensa ao direito a privacidade, não atende ao princípio da efetividade do processo. Conclu que a satisfação do crédito do exeqüente é também interesse da Justiça e dessa forma, o direito à privacidade deve ceder quando confrontado com aquele.

"Mestranda em Direito Negocial pela Universidade Estadual de Londrina. Professona da Universidade Estadual de Londmina. 
ABSTRACT: It presents problem related to inexistent properties in the excution process. Particularly regarding questions related to banking and fiscal's secrets. It investigates the juridical natute of these two species, as well as its legal frame, when instruments of right of privacy. It emphasizes the procedings that may be used by the creditor in the search of the debitor's properties, as well as the legals obstacles related to banking and fiscal's secrets. It highlights the falled civil execution as one of the hypotheses that allows restriction of the banking and fiscal's secrets. It sustains that the judges decision that refuses the request of expedition of official letters to the Federal Tax Department and to the Central Bank while aining the search for information regarding possible properties of the debitor, under the argument of defense to privacy, it does not answer to the principle of effectiveness of the process. It concludes that the satisfaction of the creditor is also the Justice's interest and this way, the right of privacy must be released when confronted with the first one.

RESUMEN: Presenta la problemática relativa a la existencia de bienes embargables en el proceso de jecución, particulamente en lo tocante al caso de los secretos bancario y fiscal. Lnvestiga la naturaleza jurídica de estos dos temas, así como su encasillamiento legal, siendo ellos especies del derecho a la vida privada. Aborda, también, los procedimientos que pueden ser adoptados por el demandante en la búsqueda de bienes del demandado, así como los óbices legales ligados a los secretos bancario y fiscal. Resalta la ejecución civil frustrada como una de las hipótesis que propician restricciones a los sigilos bancario y frscal, sostentendo que la decisión del juez que denega el pedido de oficios al Fisco y al Banco Central, visando la búsqueda de informaciones sobre eventuales bienes de propiedad del demandado, bajo el argumento de ofensa al derecho a la vida privada, no atiende al principio de la efectividad de la demanda. Concluye que la satisfacción del crédito del demandante es también un interés de la Justicia y de esa forma el derecho a la vida privada debe ceder cuando confrontado con aquél.

PALAVRAS CHAVE: Execução Civil. Privacidade. Sigilos bancário/frscal. Efetividade do Processo. Interesse da Justiç.

KEY-WORDS: Civil Execution. Privacy. Banking/Fiscal Secrets. Efectiveness of the process. Justice's Interest.

PALABRAS-LLAVE: Embargo, ejecución civil Vida privada Secretos bancario y fiscal. Efectridad de la demanda. Interés de la Justicia. 


\section{Introdução}

A questão da execução frustrada é tema que sempre suscitou a indignação do credor, mormente quando, mesmo ciente da potencial solvência do devedor, vê-se tolhido no alcance dos prováveis bens existentes.

Ainda hoje não é pacífico pelos magistrados autorizar-se a expedição de oficios dirigidos à Receita. Federal e ao Banco Central para se conferir a existência de eventuais bens/numerários em nome do devedor, invocando-se, como razão do indeferimento, o direito à privacidade.

Dentre os vários aspectos da vida privada, cabe ressaltar que o direito aos sigilos bancário e fiscal, integram o amplo direito à privacidade, tendo, portanto, fundamento constitucional, ambos inseridos no título dedicado aos direitos e garantias fundamentais (Art. $5^{\mathrm{a}}, \mathrm{X}$ e XII).

Sem pretender desnaturar os institutos, objetiva-se mostrar que o direito à inviolabilidade dos sigilos bancário e fiscal, a exemplo dos demais direitos, tem caráter relativo, e em caso de colisão com outros direitos ou interesses, devem ser submetidos ao princípio da proporcionalidade.

No âmbito processual, como adverte Cândido Rangel Dinamarco, o princípio da instrumentalidade, que tão intimamente vincula o direito processual e o direito material, se põe, modernamente, sob duplo sentido: sob prisma negativo, exige que se evitem os males do "exagerado processualismo"; e sob prisma positivo, impõe uma visão do processo "como instrumento eficaz de acesso à ordem jurídica justa, apto a realizar os seus verdadeiros escopos, jurídicos, políticos e sociais."

Também Barbosa Moreira, um dos processualistas que se empenham na luta pelo processo como veículo de efetividade da ordem jurídica material, reclama para os remédios estruturados pelo direito processual uma função que sempre atinja tal resultado prático "que assegure à parte vitoriosa o gozo pleno da específica utilidade a que faz jus segundo o ordenamento."

Entre os processualistas mais eminentes da atualidade, pode-se afirmar, sem receios, que a nota da efetividade da tutela jurídica se transformou na busca incessante de aproximar cada vez mais o processo e o direito material, sob inspiração do principio da instrumentalidade. ${ }^{3}$

Os mecanismos processuais (e nessa ordem de idéias referimo-nos à autorização judicial determinando a expedição de ofícios ao BACEN e à

1 DINAMARCO, Candido R. A instrumentalidade do processo. São Paulo, RT, 1987, p.450-451.

2 BARBOSA MOREIRA. Notas sobre o problema da efetividade do processo. In: Estudos de direito processual em homenagem a José Frederico Marques. São Paulo, Saraiva, 1982, p.203.

3 FERNANDES, Antonio Scarance. Incidente processual. Säo Paulo, RT, 1991, n. 3, p. 25. 
Receita Federal), não podem brigar com os institutos de direito material, nem podem gerar incerteza formal quanto ao modo e aos efeitos do expediente procedimental posto à disposição do titular do direito subjetivo substancial que tem necessidade de recorrer à prestação jurisdicional.

O exagerado processualismo que se distancia da verdadeira natureza do direito material e provoca incerteza em relação às partes e ao magistrado, apresenta-se como altamente nocivo aos interesses da sociedade, haja vista que o processo civil moderno caracteriza-se como meio para se atingir a paz social, informado pelos princípios da informalidade, celeridade e economia processuais.

O que se pretende discutir é a implementação da efetividade do processo nos casos em que a própria lei cria embaraços para o credor alcançar os bens que responderiam à satisfação de seu crédito, considerando as situaçốes de aparente inexistência de bens em nome do devedor e que importariam em execução frustrada.

\section{A Busca de Bens pelo Credor}

A prestação jurisdicional no processo de execução de quantia certa contra devedor solvente é a satisfação pecuniária resultante do título executivo judicial ou extrajudicial. Esta satisfação é operada, sob forma instrumental e preponderantemente, com o ato de penhora. Assim, a penhora não é o escopo do processo de execução, mas sim uma das formas com que fará desaguar a finalidade do processo desta natureza: a satisfação do dircito do credor e a extinção da relação jurídica primária.

O objeto do processo de execução por quantia certa contra devedor solvente, como já alinhavado, é a satisfação do credor pela excussão de bens do devedor. Logo, estes bens são o elo de ligação ao objeto do processo de execução, posto que, sem eles, o credor nunca verá satisfeita sua pretensão.

É corrente no processo de execução, após frustradas as diligências do oficial de justiça para penhora de bens do devedor e também após restarem negativas as tentativas do credor na busca de bens para satisfação de seu crédito, que o exeqüente requeira ao juiz a expedição de ofícios ao Banco Central e à Receita Federal, a fím de obter informações relativas às contas de depósito e declaração de bens em nome do executado. 
Ocorre que, não raras vezes, tais pedidos têm sido indeferidos, sob o fundamento de suposta violaçäo ao sigilo bancário e fiscal, cuja possibilidade de quebra limitar-se-ia às hipóteses elencadas nos respectivos dispositivos legais que tratam da matéria (Lei Complementar n. 105/2001 e Art.198 do Código Tributário Nacional).

Entretanto, não pode ser olvidado que tanto o direito à inviolabilidade do sigilo bancário, como ao sigilo fiscal, espécies do direito à privacidade, não tem caráter absoluto e imutável.

Como já ressaltado, o direito à privacidade abrange os sigilos bancário e fiscal, eis que as informações bancárias e fiscais constituem parte da vida privada do indivíduo.

Sendo, portanto, considerados direitos fundamentais, importa antes estabelecer a natureza jurídica de tais institutos e após, fixar seus limites, considerando que não há direitos absolutos.

\section{Sigilo Bancário}

\subsection{Definição e Fundamentação Jurídica}

O sigilo bancário pode ser definido "como a obrigação que têm os bancos de não revelar, salvo justa causa, as informaçôes que obtenham em virtude de sua atividade profissional"4.

No Brasil, o sigilo bancário deriva do dever profissional ${ }^{5}$ e encontra respaldo na Constituição Federal, no que tange à proteção da privacidade. ${ }^{6}$

Miguel Reale citado por Arnoldo Wald, entende ser possivel combinar o fundamento do segredo profissional com a proteção à privacidade:

Essa fundamentação não conflita, mas antes se harmoniza com a outra que aponta o sigilo bancário como uma condição do exercício de uma profissão que não subsistiria se fosse o banco obrigado, sem razão especifica e legítima, a oferecer informaçōes sobre as aplicações privadas de seus clientes, o que ficou claramente preservado no já recordado inciso XIV do art. $5^{\text {a }}$ da Carta de 1988.7

COVELlo, Sérgio Carlos. O Sigilo Bancário como Proteço à Intimidade Revista dos Tribunais, São Patlo, o. 648, p. 27-30, out. 1989 .

Cf. COVELLO, op. cit.

Cf ARAUJO, Luiz Aberto David, NUNES, Vidal Serrano Junior. Curso de Direito Constitucional.4ed. São Paulo: Saraiva: 2001, p. 104.

7 REALE apud WALD, Arnoldo. Sigilo Bancírio e os Direitos Fundamentais. Cadernos de Direito Tributário e Finanças Públicas, São Paulo, a. 22, p. 15-31, jan/mar. 1998. 
Pode-se dizer, então, que o fundamento jurídico do sigilo bancário decorre do sigilo profissional aliado ao direito à privacidade.

Constitucionalmente, a proteção ao sigilo bancário está albergada tanto no inciso X, como no inciso XII, ambos do Art. 5ª no capítulo dedicado aos direitos e deveres individuais e coletivos.

Há quem sustente, como o jurista Tércio Sampaio Ferraz Júnior que o inciso XII não se refere ao sigilo de dados, mas ao sigilo das comunicações de dados asseverando que "o objeto protegido no direito à inviolabilidade do sigilo não são os dados em si, mas a sua comunicação restringida (liberdade de negação)."

Em sentido contrário, o Prof. Ives Gandra da Silva Martins reconhece no citado inciso XII a expressão "sigilo de dados" e aponta que a mesma abarca o conceito de sigilo bancário, assinalando com tranqüilidade :

Sempre estive convencido de que a expressão "sigilo de dados" hospeda aquela de "sigilo bancário". Esta é a espécie daquele gênero. E, neste particular, me parece absolutamente correta a postura do legislador e da jurisprudência em preservar o sigilo bancário do arbítrio e admitir sua quebra sempre que houver autorização judicial.

Divergências à parte, o fato é que tanto o inciso X como o inciso XII do artigo $5^{a} \mathrm{da}$ CF têm por escopo, em última análise, a proteção do direito à privacidade $e$ intimidade e, como já ressaltado, as informações bancárias integram a vida privada dos indivíduos, tendo o sigilo bancário assento constitucional.

$\mathrm{Na}$ legislação infraconstitucional brasileira, o sigilo bancário é regulamentado pela Lei Complementar n. 105, de 10 de janeiro de $2001{ }^{10}$

Tal diploma legal têm sofrido sérios ataques em face da alegação de inconstitucionalidade de alguns de seus dispositivos, especificamente os artigos $5^{a}$ e $6^{\text {al1 }}$, o primeiro autorizando a administração tributária da União a ter acesso às informaçôes mantidas pelos estabelecimentos bancários, relativas às

\footnotetext{
${ }^{3}$ FERRAZ JUNIOR, Tércio Sampaio. Sigilo de Dados: O direto à Privacidade es Limites à Funça Fiscalizadora do Estado. Cademos de Direito Tributário e Finanças Públicas, São Paulo, n.1, ont/ dez.1992, p. 146.

"MARTINS, lyes Gandra da Silva Revista Dialetica de Direito Tributário, São Paulo, n. 1, p. 15/25.

I" Art. 1" As instituiçōes financeiras conservarão sigilo em suas operaçôes ativals e passivas e serviços prestados."

11 "Art. 5" O Poder Executivo disciplinana, inclusive quanto à periodicidade e aos limites de valor, os critérios segundo os quais as instituições financeiras informaño à administraçäo tributária da Uniăo, as operaçoes financeiras efetuadas pelos usuários de seus serviços."

"Art. 6". As autoridades e os agentes fiscais tributários da União, dos Estados, do Distrito Federal e dos Municipios somente poderäo examinar documentos, livros e registros de instituiçoes financeiras, inclusive os referentes a contas de depósito e aplicaçöes financeiras, quando houver processo administrativo instaurato ou procedimento fiscal em curso e tais exames sejam considerados indispensaveis pela autoridade administrativa competente."
} 
operações financeiras efetuadas pelos usuários de seus serviços; o segundo facultando às autoridades e agentes fiscais da União, Estados, Distrito Federal e Municípios, o exame de livros, documentos e registros de instituições financeiras, quando houver processo administrativo ou fiscal instaurado.

De fato, ao tornar acessível aos agentes tributários as informaçôes relativas às operações financeiras daqueles que são sujeitos da investigação, a lei ampliou o campo de acesso, antes permitido somente ao Poder Judiciário e às Comissões Parlamentares de Inquérito. ${ }^{12}$

Argumentos têm sido levantados a favor e contra os referidos dispositivos legais, afirmando os defensores que o sigilo bancário não pode ser obstáculo para a atividade comprobatória e fiscalizatória da administração fazendária.

Conforme argumentou a Prof ${ }^{\circ}$. Denise Lucena Cavalcante:

O sigilo bancário não pode mais servir como instrumento para proteção de delitos e fraudes fiscais, onde grandes grupos econômicos agem livremente em nosso País, contribuindo para a nossa miséria financeira e moral. Se a nova lei que permite a quebra do sigilo bancário pelo Fisco, com as devidas restrições nela impostas, for declarada inconstitucional pelo nosso Poder Judiciário, estaremos andando de marcha ré em relação às demais legislaçōes modernas. ${ }^{13}$

Aqueles que se insurgem contra a possibilidade do Fisco ter acesso às informações bancárias do particular, sustentam a inconstitucionalidade dos mencionados dispositivos, justamente por violarem o direito à privacidade, assegurado constitucionalmente. Nessa ordem, a quebra do sigilo bancário só se justificaria em se tratando de ordem judicial.

Já por diversas ocasióes, o E. Supremo Tribunal Federal reconheceu o sigilo de dados de operações financeiras como desdobramento do direito à privacidade assegurado no inciso X do Art. $5^{\text {a }}$ da Constituição Federal, só passivel de flexibilização através de ordem judicial ${ }^{14}$.

Não há dúvidas, pois, que o sigilo de dados bancários e operações financeiras constituem, pois, uma categoria do direito à privacidade, possuindo, ainda que de forma implícita, patamar constitucional, de tal modo que as exceçốes a esses direitos devem ter sempre caráter restritivo.

\footnotetext{
${ }^{12} \mathrm{O}$ Art. 33 da Lei n. 4.595/64 disciplinava o sigilo bancário, antes da edição da Lei Complementar n. $105 / 2001$.

"CAVALCANTE, Denise Lucena. Sigilo Bancário e o Devido Processo Legal. Disponivel em: Khttp// www deniselchpg.ig,com.br/artigos,hm-3k>. Acesso em: 29 jul. 2003.

${ }_{17}$ Cf. RE. n. 215301/CE. Rel: Min. Carlos Velloso. Brasília,13 de abril de 1999.
} 


\section{Sigilo Fiscal}

O sigilo fiscal decorre do dever imposto à Fazenda Pública ou seus servidores de não divulgar as informações obtidas em razão do exercício de suas funções, relativas à situação econômica ou financeira do sujeito passivo ou terceiros.

O direito ao sigilo fiscal, a exemplo do sigilo bancário, também encontra abrigo na Constituição Federal, pois neste caso, os dados fornecidos pelo contribuinte (patrimônio, renda, despesas) revelam seu modo de vida, seu estilo, suas preferências e tais atributos integram a vida privada do indivíduo.

Nas palavras do ex-procurador geral da Fazenda Nacional, Cid Heráclito de Queiroz:

[...] os dados a que se refere o preceito constitucional, são os registros dos sistemas de processamento eletrônico, que se relacionem com a intimidade do cidadão, tais como os mantidos pelos órgãos fiscais da Administração, pelas instituições financeiras,[...] assim como as declarações de renda e de bens, são verdadeiros retratos da intimidade do cidadão e as coleções desses documentos são como que álbuns reveladores da imagem intima de cada um, ao logo da vida..$^{15}$

Dessa forma, no plano constitucional, a proteção encontra guarida tanto no inciso X, como no inciso XII do Art. $5^{-a}$ da CF.

O Art. 198 da Lei n. 5.172, de 25 de outubro de 1966 (Código Tributário Nacional), com a nova redação dada pela Lei Complementar n. 104/ 2001, trata da matéria, elencando, também, as hipóteses que autorizam a quebra do sigilo.

Registre-se, ainda, que o inciso II do $\S 1 \mathrm{a}$, bem como o $\$ 2^{\mathrm{a}}$, ambos do Art. 198, têm sua constitucionalidade questionada por diversas Ações Dirctas de Inconstitucionalidade, em trâmite perante o Supremo Tribunal Federal ${ }^{16}$.

\section{A Relatividade do Direito aos Sigilos Bancário e Fiscal}

Reprisamos que não existem direitos absolutos e tanto o sigilo bancário como o sigilo fiscal admitem restriçôes, além daquelas já definidas na lei.

Em relação à quebra dos sigilos bancário e fiscal, nas hipóteses não

\footnotetext{
is QUEIROZ, Cid Herádito de O sigilo Bancirio. Revista Forense Rio de Janeiro, wol. 329, p.41-54, fev/mar/1995 ${ }^{16}$ ADIN n. 2386, 2390 e 2397.
} 
previstas pelas restrições legais, exigir-se-á do aplicador da lei o sopesamento dos interesses a serem protegidos.

Com efeito, não se discute a relatividade do direito à inviolabilidade dos sigilos bancário e fiscal, os quais devem ceder diante do interesse público, do interesse da Justiça, do interesse social.

A melhor doutrina e jurisprudência entendem, contudo, que a possibilidade de quebra dos sigilos bancário e fiscal deve ser condicionada à existência de processo judicial ou desde que tal ordem seja emanada do Poder Judiciário, sendo numerosas as decisões proferidas pelos Tribunais Superiores, estabelecendo a necessidade de autorização judicial para quebra dos sigilos bancários e fiscal. ${ }^{17}$

Dessa forma, a submissão à prévia autorização judicial permite que o julgador avalie e pondere as razões que justificariam a violação dos sigilos bancário e fiscal.

\section{A Quebra dos Sigilos Bancário e Fiscal em Face do Interesse da Justiça}

Definida a possibilidade de quebra dos sigilos bancário e fiscal em face do interesse público ou da Justiça, cumpre, antes, estabelecer quando estarão presentes tais interesses e, principalmente, se nestas situações, justifica-se a mitigação do interesse individual.

Analisar-se-á, particularmente, uma espécie do gênero, qual seja, o requerimento do exeqüente para busca de bens em nome do executado, junto ao Banco Central e à Receita Federal.

A jurisprudência nos fornece algumas situações que evidenciam a divergência de entendimento dos tribunais em relação às medidas adotadas pelo credor na busca da satisfação de seu crédito, merecendo destaque as decisões proferidas pelo Superior Tribunal de Justiça ${ }^{18}$, onde se verifica que o entendimento predominante é no sentido de preservar o sigilo fiscal e bancário, ainda que frustradas as tentativas do credor na localização de bens do devedor.

Entretanto, o Tribunal de Alçada do Paraná tem se posicionado favoravelmente à expedição de ofício à Receita Federal e ao BACEN, com vistas a possibilitar a penhora em bens do executado, inclusive com a edição da Sumula na $n^{\underline{a}}$ 03: "É legítima a pretensão do credor em obter, para efeito de penhora em processo de execução, esclarecimentos sobre a

\footnotetext{
${ }_{17}$ Cf. REsp, a, 114741/DF. Rel: Min. Milton Luiz Pereira. Brasilia, 13 de outubro de 1998 , Habeas Corpus n.15026/SC. Rel: Min. Vicente Leal. Brasília,24 de setembro de 2002

13 Cf. REsp. n. 2777/PA. Rel: Ministro Sálvio de Figueiredo Teixeira. Brasilia, 21 de agosto de 1990; REsp. n. 114741/DF. Rel: Min. Milton Luiz Pereira. Brasilia, ${ }^{9}$ de junho de 1999; AgReg. n. 225634/SP. Rel: Mia. Nancy Andrighi. Brasilia,17 de fevereiro de 2000; REsp. n. 144062/SP. Rel: Min. Francisco Pecanba Martins. Brasilia, 08 de fevereiro de 2000; REsp. n. 306570/SP. Rel: Min. Eliana Calmon. Brasilia, 18 de outubro de 2001; REsp.n. 206963/LS. Rel: Min. Garcia Vieina. Brasilia, 25 de mato de 1999.
} 
existência de bens declarados pelo devedor perante a Receita Federal”.

O cerne da questão reside no fato de se considerar ou não a satisfação do crédito do Exequente como interesse da Justiça.

De fato, um dos postulados do processo é a efetiva prestação jurisdicional. $O$ processo existe e justifica-se apenas se pensarmos que ele é necessário para instrumentalizar uma ação e reação e atingir um objetivo: substituir as pretensões resistidas pela vontade do Estado e imprimir soberania através de um ato jurídico decisório.

O processo executivo não escapa deste raciocínio. Demonstrada a certeza, liquidez e exigibilidade do negócio jurídico primário, através de documento hábil e reconhecido por lei como tal e descumprida a obrigação da relação jurídica subjacente, nasce o interesse do credor, motivando-o a provocar a jurisdição.

A provocação da jurisdição pelo interessado na solução de um litígio, implica na entrega da prestação jurisdicional, que no processo de execução por quantia certa contra devedor solvente, consiste na satisfação do crédito do exeqüente, representado pelo título executivo.

No processo de execução por quantia certa, o despacho do juiz ordenando a citação do executado para pagar ou nomear bens à penhora, reconhece, ainda que primariamente, o direito do exeqüente.

Nesse passo, se a prestação jurisdicional no processo de execução por quantia certa contra devedor solvente é a expropriação de bens do executado para satisfação pecuniária decorrente do crédito representado pelo título executivo, a efetiva entrega dessa prestação só ocorrerá com a satisfação do crédito do exeqüente.

Dessa forma, a possível frustração na expectativa de recebimento, ante a aparente inexistência de bens em nome do executado, torna, portanto, inócuo, o processo de execução.

Assim, o interesse do exeqüente na satisfação do seu crédito é também o interesse da Justiça de tornar efetiva a prestação jurisdicional, finalidade última do processo.

Com efeito, a pacificação social é um dos objetivos que caracterizam o Estado moderno, na busca do bem comum, que é seu objetivo-síntese. ${ }^{19}$

Nas palavras do mestre Cândido Rangel Dinamarco:

Grande parte dos conflitos que envolvem as pessoas expressam-se pela pretensão de um sujeito ao apossamento de um bem, resistida pelo outro sujeito. Conflitos dessa ordem só estarão eliminados, e talvez pacificados os sujeitos, quando o primeiro obtiver efetivamente o bem a que almeja, ou quando definitivamente ficar declarado que não tem direito a ele. Isso quer dizer que a função estatal pacificadora só se considera cumprida e acabada quando um desses resultados tiver sido obtido. Enquanto 
perdurar a insatisfação do credor, mesmo tendo sido reconhecido como tal, o conflito permanece e traz em si o coeficiente de desgaste social que o carateriza, sendo também óbice à felicidade da pessoa. ${ }^{20}$

E continua o professor:

[...] o ideal atingível através da execução é a produção dos mesmos efeitos que produziria a satisfação voluntária do direito pelo próprio obrigado ou por terceiro, ou seja, a realização da vontade da lei em seu resultado econômico objetivo. É claro que a execução será, em cada caso, mais ou menos frutífera, o que dependerá da solicitude do órgão jurisdicional, da eficiente cooperação do exequente, das possibilidades do patrimônio do executado, da conduta leal deste e de tantos outros fatores. ${ }^{21}$

De fato, o princípio da máxima utilidade da atuação jurisdicional " assume especial importância no processo executivo, na medida em que, neste, a atuação da sanção e a satisfação do credor só são concretamente atingidos mediante obtenção de resultados materiais, fisicamente tangíveis: só se estará dando a quem tem direito tudo aquilo e exatamente aquilo que the cabe quando se consegue, mediante meios executivos, modificar a realidade, fazendo surgir situação concreta similar, quando não idêntica, a que se teria com a observância espontânea das normas."22

A situação em destaque, o acesso às informações mantidas pelo Banco Central e pelo Fisco, ainda que protegidas pelos sigilos bancário e fiscal, configura a possibilidade de exercício desse direito pelo exeqüente e nesse caso, o julgador, diante de um confronto de interesses, bens ou valores constitucionais, deve realizar o chamado sopesamento ou avaliação ponderada dos fins, conforme construção da doutrina constitucional alemã. ${ }^{23}$

Na verdade, seguindo o escólio do constitucionalista Celso Bastos, "o importante é lembrar que o juizo sobre o caráter excepcional dessa restrição é levado a efeito pelo Poder Judiciário, uma vez que qualquer ordem ou medida a ser tomada é sempre feita por intermédio dele. Ele é o único a ter condições para dar a cada caso o julgamento adequado." 24

Ao buscar a convivência de direitos fundamentais que se anulam reciprocamente, o jurista terá de afastar ou diminuir a força de um deles, sem aniquilá-lo, para viabilizar a realização do outro.

\footnotetext{
${ }^{20} \mathrm{Id} .$, p. 95, grifos nossos.

2! Id, p. 107, grifos nossos.

2. WAMBIER, Luz Rodrigues (coord.). Cunso Avangado de Processo Civil, II, 2. ed, RT, São Paulo,1999, p121.

23 GRABITZ apud THRCIO SAMPAIO, op cit, $\mathrm{p} .145$.

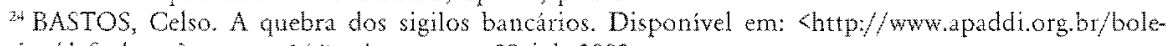
tins/defautrasp?numero $=164>$. Acesso en: 29 jul. 2003 .
} 


\section{Conclusão}

O direito à privacidade abrange o sigilo bancário e o sigilo fiscal, eis que as informações bancárias e fiscais constituem parte da vida privada do indivíduo.

$O$ direito aos sigilos bancário e fiscal tem fundamento tanto no inciso $\mathrm{X}$, quando no inciso XII, ambos do Art. $5^{\mathrm{a}}$ da Constituição Federal.

O pedido de quebra dos sigilos bancário e fiscal, quando requeridos judicialmente, nas hipóteses não previstas pela lei, exige do juiz um sopesamento dos interesses a serem protegidos.

A tutela jurisdicional no processo de execução por quantia certa consiste na satisfação do crédito do exeqüente, representado pelo título executivo.

Dessa forma, considerando que o caráter jurisdicional da execução reside na atuação da vontade concreta do direito, a satisfação do exeqüente é também interesse da Justiça, justificando-se a busca das informações bancárias e fiscais em nome do executado, com vistas à realização do resultado pretendido com a execução.

No caso específico do executado que oculta seus bens, frustrando a execução, os sigilos bancário e fiscal, ainda que integrantes do direito à privacidade, devem ceder ante à realização da efetiva prestação jurisdicional, prevalecendo, nesse caso, o interesse da Justiça.

\section{BIBLIOGRAFIA}

ARAUJO, Luiz Alberto David; NUNES JR., Vidal Serrano. Curso de Direito Constitucional. 4. ed., rev. atual. São Paulo: Saraiva, 2001.

BARBOSA MOREIRA. Notas sobre o problema da efetividade do processo. In: Estudos de direito processual em homenagem a José Frederico Marques. Saraiva. São Paulo: 1982, p.203.

BASTOS, Celso Ribeiro. A quebra dos sigilos bancários. Disponível em:http:// www.appadi.org.br/boletins/default.asp?numero=164. Acesso em:29 julho 2003. BRASIL. Constituição (1988). Constituição da República Federativa do Brasil. 30. ed. atual., amp. São Paulo: Saraiva, 2003.

BRASIL. Lei Complementar n. 104, de 10 de janeiro de 2001. Disponível em: http:/ /www.planalto.gov.br/ccivil_03/Leis/LCP/Lcp104.htm. Acesso em 29 jul. 2003. BRASIL. Lei Complementar n. 105, de 10 de janeiro de 2001. Disponível em: http:/ /www.planalto.gov.br/ccivil_03/Leis/LCP/Lcp105.htm >. Acesso em 29 jul. 2003. CAVALCANTE, Denise Lucena. Sigilo Bancário e o Devido Processo Legal. Disponível em: $\langle$ http://www.deniselc.hpg.ig.com.br/artigos.htm-3k $>$. Acesso 
em: 29 julho 2003.

COVELLO, Sérgio Carlos. O Sigilo Bancário como Proteção à Intimidade. Revista dos Tribunais. São Paulo, n. 648, p.27-30, out.1989.

DINAMARCO, Cândido Rangel. A Instrumentalidade do Processo. RT São Paulo: 1987 , P. 450-451.

Execução Civil. 4. ed., São Paulo: Malheiros. 1994.

FERNANDES, Antonio Scarance. Incidente processual. RT. São Paulo:1991. n. 3, p. 25. FERRAZ JUNIOR, Tércio Sampaio. Sigilo de Dados: O Direito à Privacidade e os Limites à Função Fiscalizadora do Estado. Cadernos de Direito Tributário e Finanças Públicas . São Paulo, n. 1, p. 141-154, out./dez. 1992.

MARTINS, Ives Gandra da Silva . Revista Dialética de Direito Tributário. São Paulo, n. 1, p. 15-25.

QUEIROZ, Cid Heráclito de. O sigilo bancário. Revista Forense. Rio de Janeiro, v. 329, p. 41-54, fev./mar. 1995.

WALD, Arnold. Sigilo Bancário e os Direitos Fundamentais. Cadernos de Direito Tributário e Finanças Públicas. São Paulo, n. 22, p. 15-31, jan./mar. 1998. WAMBIER, Luiz Rodrigues (org). Curso Avançado de Processo Civil, v. II. 2. ed. São Paulo: RT. 1999. 